\title{
Arrangement and safe operation of auto-roads on a construction site
}

\author{
Ivan Doroshin ${ }^{1, *}$, Boris Zhadanovskiy ${ }^{1}$, Ruben Kazaryan ${ }^{1}$ \\ ${ }^{1}$ Moscow State University of Civil Engineering, 26, Yaroslavskoye sh., 129337, Moscow, Russia
}

\begin{abstract}
Traditional and innovative ways of constructing temporary roads at a construction site are considered. The basic principles of the preparation of construction operations are given, which should be taken into account at this stage. Particular attention is paid to the preparation of the construction of the facility and preparation for the construction and installation works. The organization of designing construction roads, temporary and permanent, is considered. Methods for determining the parameters of construction roads are described. The main technical indicators of construction roads are given. Dangerous areas of the roads are indicated. The main purpose of the research is to generalize and systematize the modern ways of arrangement and operation of auto-roads on a construction site. For carrying out of the study the methodical and scientific literature on the subject was analyzed, and also the statistic methods of data investigation were used. The main results of the research is the accomplishment of estimation of expenses on arrangement of autoroads, the indication of order of working out of design of the auto-roads, also the indication of necessity of use of permanent roads as temporary. The design of temporary and permanent construction roads is very important because of their greater use in comparison with railway transport and a great influence on the supply of construction materials.
\end{abstract}

\section{Introduction}

Studies have shown that Intra-constructional transportation in modern civil engineering in $70 \%$ of cases is carried out by means of a road transport on temporary roads and roads arranged for the permanent operation of the building [1,2]. The design of these roads is carried out taking into account special requirements at the stage of preparation of project documentation in the section of the project of the organization of construction. The construction site should be provided with convenient entrances and intra-constructional roads for organizing an uninterrupted supply of constructional materials, machinery and equipment.

The main and most rational requirement for the design of inter-constructional roads for temporary use should be considered the requirement of their structure in the required volumes for operation all year round in various climatic conditions [3,4,5]. When determining the length of temporary roads, it should be borne in mind that they are going to

\footnotetext{
* Corresponding author: ivandoroshin@rambler.ru
} 
be dismantled, which means additional labor costs for dismantling, increasing the energy and material consumption of construction production.

The question of construction roads is also tied with ecological questions and allowable level of noise [6,7]. The problem concerns layout planning and apparition of road dust $[8,9]$. It is very important to control the construction site activities [10,11]. The condition of roads affects on the safety of labor $[12,13]$ and on timely supply of materials $[14,15]$.

The objective of the current study was to generalize and find the most rational ways of arrangement of auto-roads on a construction site.

\section{Materials and methods}

For carrying out of the study on the theme of arrangement and operation of temporary roads on construction site the methodical and scientific literature on the subject was analyzed, and also the statistic methods of data investigation were used on the example of different construction processes and sites.

\section{Results}

Given the above, they should be arranged in the direction of the roads remaining at the construction site for future permanent operation as much as possible.

For intra-constructional transportation, usually is used general-purpose and specialized vehicles.

The construction site should have convenient access roads and internal roads for the uninterrupted supply of materials, machinery and equipment throughout the construction works at any time of a year and in any weather. Roads have particular importance in stream construction when assembling buildings according to hourly schedules. In these cases, in a decisive extent the entire course of work depends on the timely arrangement and quality of the entrance.

Permanent roads are constructed after the end of the vertical land levelling of the territory, the installation of drains and other utilities. An exception may be shallow communications: outdoor lighting cables, telephone, dispatch, etc. Prior to the start of a road works, it is necessary to carry out vertical land levelling in a way to protect the subgrade from destruction.

Permanent entrances often do not completely provide construction due to the mismatch of the trace and dimensions. In these cases, temporary roads are arranged. Temporary roads are built at the same time as those permanent roads that are designed for construction vehicles: both of the roads make up a single transport network that provides a through or ring traffic pattern. Temporary roads are the most expensive part of temporary structures. Based on a data that "NIIMosstroy" provides, about $1 \%$ is spent on the construction of temporary roads even with the full and timely arrangement of constant access roads, and taking into account the cost of repairing permanent roads, it is up to $2 \%$ of the total estimated construction cost. Therefore, reducing the cost of construction roads is the main task in the design of the construction master plan.

The construction of permanent and temporary roads should be carried out in the order of priority provided by the time schedules. By the time the construction of the underground parts of the buildings begins, the entrances to them should be ready.

Design of construction roads as part of the construction master plan is carried out in a certain sequence:

1. Development of traffic patterns and the location of roads in the plan;

2. Defining of parameters of roads; 
3. Establishment of hazardous areas;

4. Defining of additional conditions;

5. Designing the structure of roads;

6. The calculation of the volume of work and the necessary resources.

The traffic plan and the location of the roads in the plan should provide access to the coverage area of the assembly and loading and unloading mechanisms, to the means of vertical transport, enlargement assembly sites, warehouses, workshops, mechanized installations, welfare premises, etc. When designing a traffic plan it is necessary to use existing and planned roads as much as possible. Construction roads must be circular and at dead-end entrances there should be arranged turning areas. Such sites design for non-ring sections of permanent existing and planned roads. As the object is put into operation, the traffic pattern is revised to prevent the movement of construction vehicles through the populated part of the residential quarter or existing enterprise.

When tracing roads, the minimum distances must be observed: between the road and the warehouse area $-0.5 \ldots 1.0 \mathrm{~m}$; between the road and crane runways $-6.5 \ldots 12.5 \mathrm{~m}$ (this distance is taken based on the size of the crane jib and the rational mutual placement of the crane - warehouse - road); between the road and the axis of the railway - $3.75 \mathrm{~m}$ (for normal gauge) and $3.0 \mathrm{~m}$ (for narrow gauge); between the road and the fence enclosing the construction site - at least $1.5 \mathrm{~m}$; between the road and the edge of the trench based on the properties of the soil and the depth of the trenches at a standard depth of laying for loamy soils $-0.5 \ldots 0.75 \mathrm{~m}$, and for sandy-1.0 $\ldots 1.5 \mathrm{~m}$.

It is unacceptable to place temporary roads above the underground engineering networks and in close proximity to the laid underground utilities, because this leads to sedimentation of slopes or backfill and deformation of roads. If the project provides for the parallel arrangement of temporary roads and communications, it is recommended that first of all arrange temporary roads for the purpose of their usage in the delivery of materials and products for network laying.

Entrances (exits) of vehicles, driving directions, U-turns, passing sights, parking at unloading, anchor dimensions, and also the places of installation of signs ensuring the rational use and safety of transport should be clearly marked on the master plan with the appropriate conventional signs and inscriptions. All these elements must have snap dimensions.

The parameters of temporary roads are: the number of lanes, the width of the road and carriageway, the radius of curvature, the estimated visibility (Table 1).

The width of the carriageway of transit roads is taken into account the dimensions of the slabs: single-lane $-3.5 \mathrm{~m}$, two-lane with widenings for parking at unloading $-6.0 \mathrm{~m}$. When using heavy machines with a carrying capacity of $25 . . .30 \mathrm{t}$ and more (MAZ-525, BelAZ540 , etc.) the width of the carriageway isincreased to $8 \mathrm{~m}$. In the process of designing the master plan, the width of the permanent roads should be checked and, if it is necessary, increased with inventory plates. On sections of roads where one-way traffic along the ring is organized within visibility, but not less than $100 \mathrm{~m}$, there are arranged sites with a width of $6 \mathrm{~m}$ and a length of up to $18 \mathrm{~m}$. The same sites are performed in the unloading zone of materials with any type of vehicle traffic.

The radii of curvature of the roads are determined based on the shunting properties of cars and road trains, in other words, their turning ability when moving forward without reverse gear. Insufficient external radius of curvature $(R=6 \ldots 8)$ leads to the destruction of corridors. Such rounding is sufficient when vehicles without trailers are used. Modern construction is served by large vehicles such as panel trucks and pipe trucks and special tractors for the transportation of cranes. So, road trains based on ZIL cars have a carrying capacity of $12 \ldots 25 \ldots 30 \mathrm{t}$ and a length of $9 \ldots 15 \mathrm{~m}$. 
Table 1. Key technical indicators of construction roads.

\begin{tabular}{|l|c|c|}
\hline \multirow{2}{*}{\multicolumn{1}{|c|}{ Name }} & \multicolumn{2}{|c|}{ Indicators for the number of lanes } \\
\cline { 2 - 3 } & $\mathbf{1}$ & $\mathbf{2}$ \\
\hline $\begin{array}{l}\text { Width of, } \mathrm{m} \\
\text { lanes }\end{array}$ & 3.5 & 3 \\
\cline { 2 - 3 } roadway & 3.5 & 6 \\
\cline { 2 - 3 } subgrade & 6 & 8.5 \\
\hline The greatest longitudinal slopes, 0/00 & 100 & 100 \\
\hline The smallest radii of the curves in plan, $\mathrm{m}$ & 12 & 12 \\
\hline Maximum design visibility, $\mathrm{m}$ & 50 & 30 \\
road surface & 100 & 70 \\
\hline oncoming car & & \\
\cline { 2 - 3 }
\end{tabular}

A number of cars without trailers, such as YaAZ-210, have two rear axles, as a result of which their length increases to $9 \ldots 10 \mathrm{~m}$. The radii of the curves adopted for constant intraquarter roads are insufficient and should be increased. The minimum radius of curvature for building passages is $12 \mathrm{~m}$. But with this radius, the driveway width of $3.5 \mathrm{~m}$ is insufficient for the movement of road trains, and therefore it is necessary to broaden the passageways within the curves (overall corridors) to $5 \mathrm{~m}$.

Although the requirements for temporary roads are less stringent than for permanent ones, such regulation still exists. The calculated visibility in the direction of travel for single-lane roads should be at least $50 \mathrm{~m}$, and the side (at the intersection) $-35 \mathrm{~m}$.

Hazardous areas of roads are set in accordance with safety standards. A hazardous zone of a road is considered to be its part that falls within the limits of the cargo movement zone or the installation zone. These sections of roads are distinguished by double hatching on the master plan. The through passage of vehicles through these sections is prohibited, and after the application of the dangerous zone of the road, bypass routes should be designed.

Additional conditions in the development of construction roads are aimed at ensuring safe traffic conditions on roads adjacent to the construction, and entry (exit) to construction sites, as well as the rational use of transport inside the construction site. In the first case, this designation is indicated by the corresponding signs in construction sites and on the drawing of the master plan of the entrance (exit) to the object, speed limit, local narrowing of the road, etc. When coordinating the master plan, the part of the design decisions is checked by the traffic safety departments of the local Ministry of Internal Affairs.

Construction organizations establish special signs for directions from the main highways to the places of unloading, indicating on the signs the name of the corresponding object (section) and the location of the cargo receiver.

The construction of permanent roads used during the construction period must correspond to the loads arising from the movement of heavy vehicles. The main reason for the destruction of permanent and temporary roads is the discrepancy between the adopted instructions and the actual operating conditions. Permanent intra-quarter roads are designed for transport with a wheel pressure of $35 \mathrm{kN}$ at a real $45 \ldots 60 \mathrm{kN}$ or more. In addition, often do not take into account the soil conditions, while loamy and dusty soils require thickening of the underlying layer and strengthening the design of driveways. Do not underestimate the loads from tracked vehicles, whose destructive effect on driveways is much greater than from vehicles, despite the slight pressure on the coating $(250 \ldots 500$ 
$\mathrm{kPa}$ ). Due to the flexibility of the tracks, this pressure is unevenly distributed and actually reaches $20,000 \mathrm{kPa}$. The coating is especially damaged when passing through bumps, when turning and entering (exiting) across the road.

When using permanent roads as construction roads, the thickness of concrete preparation with concrete with a strength of $200 \mathrm{~kg} / \mathrm{cm} 2$ should be increased to $18 \ldots 21$ $\mathrm{cm}$. Reinforcing permanent roads makes construction more expensive, but to a much lesser extent than the cost of temporary ones.

Permanent driveways for use during the construction period are carried out in two stages. First, make a concrete base and lay the bottom layer of the asphalt concrete pavement. Construction transport moves along the lower layer of the coating, arranged from coarse-grained dense asphalt concrete mixtures. By the time the site development is completed and the buildings and structures are commissioned, the lower layer is being repaired and the upper layer of the coating is made of asphalt concrete sand mixtures.

One of the important structural elements of industrial buildings is concrete or reinforced concrete preparation for floors. Such preparation with a thickness of $20 \ldots 25 \mathrm{~cm}$ in many cases replaces the foundations for technological equipment in the workshops of the electrical, light and textile industries, mechanical repair shops, etc. The use of preparation for floors for construction needs significantly reduces the cost of temporary expensive and enhances the culture of building production.

In some cases, it turns out to be beneficial, at the expense of funds for temporary structures, to strengthen the design of preparation for floors (by additional reinforcement or by increasing the thickness of concrete).

The design of temporary roads, depending on specific conditions, can be of the following types: natural ground profiled; soil; improved design; with hard coating; from prefabricated reinforced concrete inventory slabs. The choice of this or that type of road depends on the traffic intensity, type and weight of cars, soil bearing capacity and hydrogeological conditions and is ultimately determined by economic calculation.

Profiled dirt roads are arranged at a low traffic intensity (up to 3 cars per hour in one direction) - in favorable soil and hydrogeological conditions. Such roads are used in linear construction: in the construction of pipelines, power lines (transmission lines), for small dispersed objects in rural and civil construction. Profiling of the carriageway is carried out to drain water during precipitation and melting ice and snow. Cross slope (40 .. 60\%) is performed using a grader. Dirt roads can be built in the shortest possible time and with the lowest cost. Their strength depends on the composition of the soil - the ratio of sand-gravel and clay parts.

Dirt roads experiencing heavy loads or in less favorable conditions are strengthened with gravel, slag, an optimal sand-gravel-clay mixture, clay firing, an addition of peat, binders (black) and cement. Gravel or other additives are poured with or without a trough device in one or two layers, followed by compaction with a roller. When reinforcing the soil with black binders, such as bitumen or tar, they mix the base soil with binders at the place of work or in the factory. In the latter case, soil-asphalt is obtained. Cement stabilization gives good results in sandy and sandy loamy soils.

A common way to strengthen roads in clay soils consists of a series of sequentially performed operations: layer-by-layer plowing of roads, giving them the necessary slopes, sanding with a layer of $4 \ldots 5 \mathrm{~cm}$, mixing clay with sand using a disk harrow, re-profiling and rolling. This cycle of work is carried out from two to four times. On soft soils, swamps, and in other similar cases, fashin lining are arranged (fashina - bundles of rods), a continuous transverse flooring or a rut covering of beams, lying, etc. Temporary cobblestone roads are not suitable due to their high labor intensity. More common are temporary roads from gravel fractions up to $70 \mathrm{~mm}$. 
Construction temporary roads under an installed load of 12 tons per axle are best constructed from prefabricated reinforced concrete slabs. These slabs are laid on a sandy bed. An attempt to save due to the thickness of the underlying layer leads to large losses due to breakdown of road slabs, disruption of traffic and difficulties in removing slabs at the end of construction. The thickness of the sand layer depends on the group of soil of the subgrade and the degree of moisture and is assigned about $10-25 \mathrm{~cm}$.

It is necessary to provide local drainage of surface water from temporary roads by creating slopes when profiling the subgrade, arranging trays, etc.

Typically, reinforced concrete slabs with unstressed reinforcement with a thickness of $16 \ldots 18 \mathrm{~cm}$ are used. These slabs with a large consumption of armature actually have a one-two-fold turnover instead of the five-six-fold stipulated in the estimates, which affects the cost of construction and installation works. Significantly better qualities are possessed by prestressed concrete slabs. Although they are somewhat more expensive, but due to their three - fourfold turnover, higher efficiency is achieved.

The safety and quality of roads from prefabricated plates are greatly facilitated by welding or twisting the plates together. This is especially important when tracked vehicles are used at the facility.

When crossing the underground engineering networks, trenches under the road should be covered with sand throughout the entire depth. If this condition cannot be fulfilled, you should go through the intersection with a certain rise, the value of which should be proportional to the coefficient of loosening of the soil 3. As the soil is compacted, this section of the road in the longitudinal direction will take a horizontal position. The connection of the plates 1 to each other in these places is absolutely necessary. All these additional works require little cost and pay for themselves. At the last stage of turnover, it is advisable to lay the slabs on a permanent road as a base for an asphalt concrete pavement.

The calculation of the volume of work and resources necessary for the construction of temporary roads is carried out in an explanatory note. In the explication of the master plan, the volumes of temporary roads for each type are written in separate positions.

The value of production stocks of building materials and prefabricated elements for building construction roads depends on many factors, including the accepted organization of work (installation "on wheels" or from the on-site warehouse, type of vehicles, ratio of one-time need and carrying capacity of a transport unit, local conditions, availability and condition of improved access roads, transportation ranges, etc.)

The level of stock of materials at the on-site warehouse can range from zero (for example, when installing road plates "off the wheels") to the total demand for materials for the volume of construction of a temporary or permanent road at a construction site.

\section{Discussion}

We also stated in this article, that there exist many attempts to save decreasing the underlying layer, when the road is built from prefabricated reinforced concrete slabs. According to the investigation conducted in this article it may cause large losses because of the breakdown of slabs, disruption of traffic, etc. So the thickness of the layer of sand must consider the group of soil below and degree of moisture and cannot be less than 10-25 cm.

Inter-constructional roads, built according to such requirements can surely provide the operation all year round in various climatic conditions. The results, obtained in this study, are very important, because their use can significantly reduce the cost of the whole construction. In the next research it is necessary to calculate the effectiveness of use of permanent roads as temporary on the stage of construction.

The related facts are the most important conditions of the successful operation of autoroads on a construction site. 


\section{Conclusions}

Thus, when organizing construction work, a very important issue is the design of temporary and permanent construction roads, primarily because of their greater use in comparison with railway transport and a significant impact on the uninterrupted supply of construction materials. The very important question, that needs further research is the possibility of use of constant roads that will function in future as temporary roads.

\section{References}

1. R.R. Kazaryan, MATEC Web of Conferences 239, 02006 (2018) https://doi.org/10.1051/matecconf/201823902006

2. R.R. Kazaryan, MATEC Web of Conferences 193, 01008 (2018) https://doi.org/10.1051/matecconf/201819304023

3. J. Hong, H. Kang, S. Jung, S. Sung, T. Hong, H. Park, D.-E. Lee, Building and Environment 170, 106636 (2020) https://doi.org/10.1016/j.buildenv.2019.106636

4. H.O. Onubi, N. Yusof, A.S. Hassan, Journal of Cleaner Production 254, 120170 (2020) //doi.org/10.1016/j.jclepro.2020.120170

5. J. Hong, T. Hong, H. Kang, M. Lee, Energy Procedia 158, 5092-5096 (2019) https://doi.org/10.1016/j.egypro.2019.01.637

6. M. Suchocka, P. Jankowski, M. Blaszczyk, Urban Forestry \& Urban Greening 46, 126436 (2019) https://doi.org/10.1016/j.ufug.2019.126436

7. X. Ning, J. Qi, C. Wu, W. Wang, Journal of Cleaner Production 222, 218-230 (2019) https://doi.org/10.1016/j.jclepro.2019.03.018

8. K. Schwabe, J. Teizer, M. Konig, Automation in Construction 97, 205-219 (2019) https://doi.org/10.1016/j.autcon.2018.10.012

9. Y. Ma, M. Gong, H. Zhao, X. Li, Science of The Total Environment 698, 134243 (2020) https://doi.org/10.1016/j.scitotenv.2019.134243

10. H. Omar, L. Mahdjoubi, G. Kheder, Computers in Industry 98, 172-182 (2018) https://doi.org/10.1016/j.compind.2018.03.012

11. S. Bang, H. Kim, H. Kim, Automation in Construction 84, 70-80 (2017) https://doi.org/10.1016/j.autcon.2017.08.031

12. M. Grill, K. Nielsen, Safety Science 114, 148-159 (2019) https://doi.org/10.1016/j.ssci.2019.01.008

13. S.C. Lee, J.H. Kim, J.Y. Hong, Building and Environment 152, 17-27 (2019) https://doi.org/10.1016/j.buildenv.2019.02.005

14. M. Nahangi, Y. Chen, B. McCabe, Safety Science 113, 382-388 (2019) https://doi.org/10.1016/j.ssci.2018.12.005

15. O. Osypchuk, S. Iwan, Transportation Research Procedia 39, 389-397 (2019) https://doi.org/10.1016/j.trpro.2019.06.041

16. I.A. Zolotar, Ensuring the reliability of roads in terms of strength during their design, construction and operation (Military Academy of Logistics and Transport, St. Petersburg, 1996)

17. Yu.N. Ivanov, V.V. Tokarev, A.P. Uzdemir, The mathematical description of the elements of the economy (Fizmatlit, Moscow, 1993) 
18. R.R. Kazaryan, B.A. Levin, Fundamentals of the organization of planning and management of roads (MIIT Publishing House, Moscow, 2018)

19. Urban Planning Code of the Russian Federation (Prospect Publishing House, Moscow, 2017)

20. Russian Federation Standard SP 133.30.48 "Organization of construction"

21. P.P. Oleynik, B.V. Zhadanovsky, The construction of monolithic structures of buildings and structures (Publishing house MISI-MGSU, Moscow, 2018)

22. P.G. Grabovy, Reconstruction and updating of the existing development of the city (DIA Publishing House, Moscow, 2006)

23. The state program of the Russian Federation "Energy Saving and Improving Energy Efficiency for the Period Until 2020"

24. P.P. Oleinik, B.F. Shirshikov, Design of the organization of construction and production of installation works: a textbook for universities (MGSU, Moscow, 2010)

25. Russian Federation Standard SP 12-136-2002

26. Russian Federation Standard SNiP 12-03-2001 Labor safety in construction. Part 1. General requirements

27. Russian Federation Standard SNiP 12-04-2002 Labor safety in construction. Part 2. Construction production

28. Russian Federation Standard STO NOSTROY 2.33.14-2011 Organization of construction production. General Provisions

29. Russian Federation Federal Law No. 261-FZ (2009)

30. V.N. Afanasyev, V.B. Kolmanovsky, V.R. Noses, The mathematical theory of designing control systems. Textbook (Higher School, Moscow, 2003)

31. I.A. Zolotar, Ensuring the reliability of roads in terms of strength during their design, construction and operation (Military Academy of Logistics and Transport, St. Petersburg, 1996)

32. Yu.N. Ivanov, V.V. Tokarev, A.P. Uzdemir, The mathematical description of the elements of the economy (Fizmatlit, Moscow, 1993) 